\title{
SIAPA ITU WISATAWAN? \\ MEMAKNAI PERKEMBANGAN KONSEPTUAL DAN PRAKTIS DALAM STUDI PARIWISATA
}

\author{
Putu Diah Sastri Pitanatri', Made Uttari Pitanatri ${ }^{2 *}$ \\ 1Program Studi Administrasi Perhotelan, Politeknik Pariwisata Bali \\ 2Program Studi Manajemen Divisi Kamar, Politeknik Pariwisata Bali \\ Jl. Darmawangsa Kampial, Nusa Dua, BALI \\ 1 diahsastri@gmail.com, 2*) uttari.pitanatri@gmail.com \\ *) Corresponding Author
}

Received: June, 2021

Accepted: June, 2021

Published: July, 2021

\begin{abstract}
In early 2020, the terminology of who is a tourist has become a debate again when the Covid19 pandemic broke out. The question arises whether the locals "deserve" the title "tourists"? Whether they are included in the category of domestic tourists? Are they categorized as tourist? With the rapid development of the understanding of this terminology, several questions have arisen that have led to the calculation of the number and distribution of tourists in travel destinations. Therefore, this work aims to unravel the tangled threads using the basic conceptual approach of tourism terminology. The literature study method is carried out by bibliometric examination. Hopefully this article provides a clearer construction to reduce confusion over the use of the term "tourist".
\end{abstract}

Keywords: terminology, tourists, construct

\begin{abstract}
Abstrak
Terminologi siapa itu wisatawan kembali menjadi pertanyaan saat pandemi Covid-19 merebak pada awal tahun 2020 Pertanyaan muncul apakah masyarakat lokal "layak" menyandang gelar "wisatawan"? Apakah mereka termasuk dalam kategori wisatawan domestik? Atau mereka tidak masuk kategorisasi sama sekali? Berbagai pertanyaan muncul dengan perkembangan pemahaman terhadap terminologi ini yang demikian pesatnya. Implikasinya adalah perdebatan dalam perhitungan jumlah dan distribusi wisatawan di destinasi. Paper ini mencoba untuk mengurai benang kusut dengan mempergunakan pendekatan konsep dasar dari wisatawan. Metode studi literatur dengan mengkaji studi bibliometric dipergunakan. Tulisan ini diharapkan dapat memberi konstruk yang lebih jelas untuk mengurangi kebingungan penggunaan terminologi "wisatawan".
\end{abstract}

Kata Kunci: terminologi, wisatawan, konstruk

\section{PENDAHULUAN}

Paradox dari definisi wisatawan sebenarnya sudah mulai muncul pada tahun 1970-an saat pariwisata baru menjadi sebuah kajian oleh para sosiolog (Tribe \& Liburd, 2016). Begitu banyak terminologi yang berusaha mendefinisikan siapa itu "wisatawan" 
yang akhirnya kemudian berakhir pada kebingungan definisi wisatawan itu sendiri. Hal paling mendasar adalah perbedaan konsep antara akademisi dengan apa yang menjadi pemahaman publik atau pendekatan praktis (McCabe, 2005). Belum lagi ada berbagai terminologi baru seperti wisatawan gastronomi (McCabe, 2019; Pitanatri \& Putra, 2016), wisatawan hybrid (Boztug et al., 2015), wisatawan flashpacker (Paris, 2012; Pitanatri, 2020) dan masih banyak lagi. Pertanyaan yang muncul dari fenomena ini, bukankah wisatawan adalah mereka yang tidak sedang bekerja?

Hal yang sama juga muncul setelah pandemi covid-19 merebak. Di Indonesia muncul terminologi "wisatawan lokal" yang menjadi populer dan digadang menjadi salah satu cara menciptakan resiliensi pariwisata pasca pandemi. Pun saat masyarakat local destinasi melakukan aktivitas berwisata jarak dekat yang menginap; misalnya populer dengan istilah staycation (Kompas, 2020; Ramdhani, 2020). Pertanyaan yang kemudian muncul, apakah mereka masih dikategorikan sebagai resident atau sudah masuk dalam kategori tourist? Apakah saat mereka menginap sudah termasuk dalam perhitungan Length of Stay (LOS)? Bukankah nantinya hal tersebut akan semakin memperpuruk perhitungan lama tinggal yang sudah selalu menurun tiap tahunnya? Serta berbagai pertanyaan lainnya muncul karena indikasi salah kaprah penyebutan wisatawan ini.

Jika merujuk kembali ke terminologi dari UN World Tourism Organisation (UNWTO) tentang Tourism Satellite Accounts (TSA), kategorisasi wisatawan hanya berdasarkan apakah mereka layak atau tidak masuk kedalam perhitungan wisatawan mancanegara dan dapat dimasukkan dalam statistik masingmasing negara (UNWTO, 2004) sebagaimana yang tampak pada gambar 1 di bawah ini.

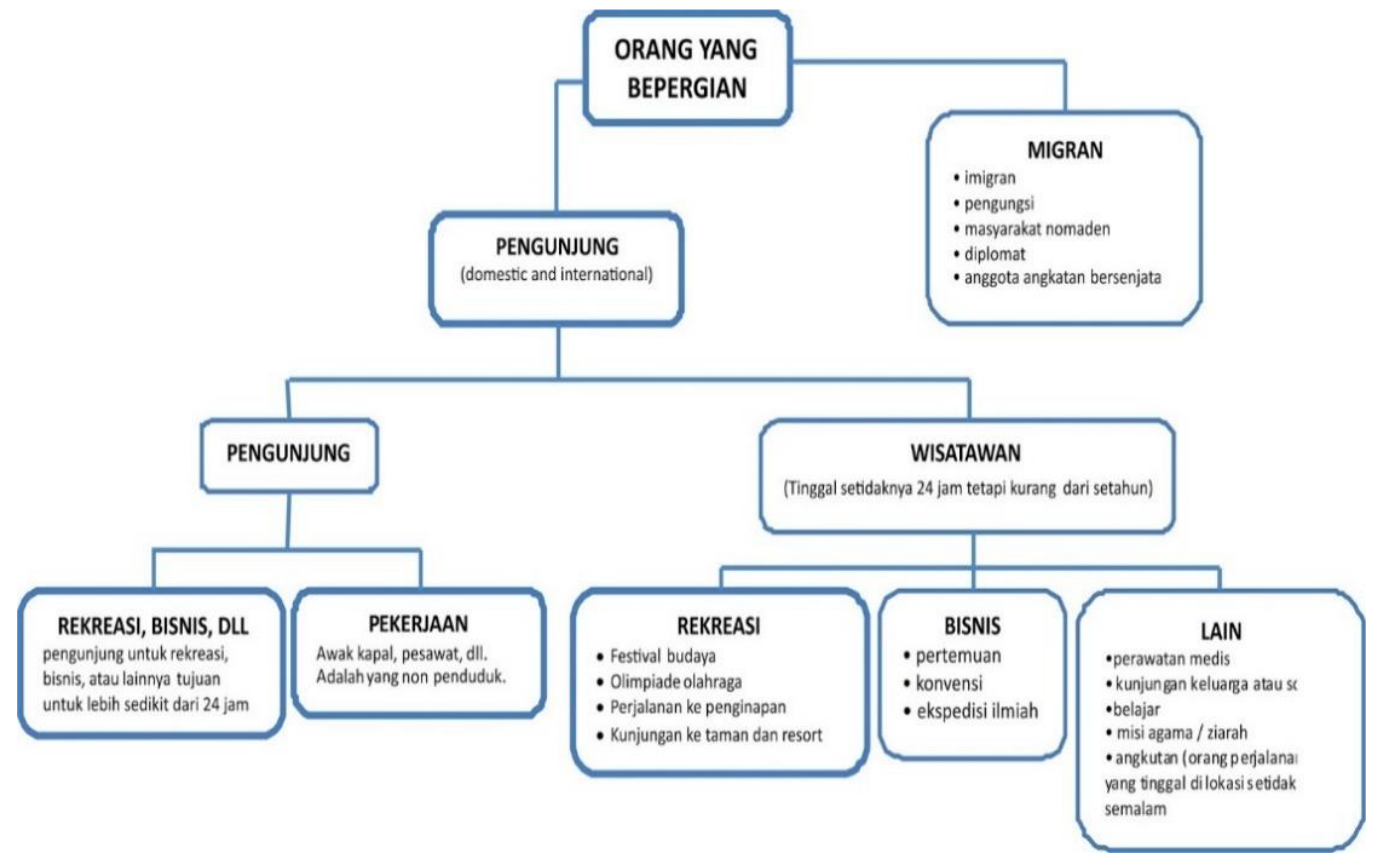

Gambar 1. Klasifikasi Wisatawan Internasional menurut UNWTO [Sumber : UNWTO, 2004]

Melihat TSA di atas, beberapa peneliti seperti McCabe (2009), Glaesser et al., (2017), Richards dan (2018) yang mengkritisi UNWTO karena mengeluarkan klasifikasi tersebut tanpa mempertimbangkan aspek-aspek dalam berwisata. Misalnya, apabila seorang diplomat pada saat weekend berlibur ke salah satu pulau tempat ia ditugaskan, apakah ia tidak termasuk dalam kategori 
wisatawan? Belum lagi berkembangnya beragam pandangan tentang esensi dari kegiatan wisatawan. Apakah mereka yang sedang melakukan perjalanan bisnis juga dianggap sebagai wisatwan, misalnya wiatawan MICE? Pertanyaan yang sama juga meliputi perkembangan kegiatan pariwisata seperi voluntourism, dark tourism, grey tourism dan sebagainya; yang turut mempertanyakan esensi dari terminology "siapa itu wisatawan".

Apalagi saat ini juga berkembang istilah virtual tourism yang melahirkan wisatawan virtual semakin menambah diskusi terhadap terminologi ini. Wisatawan virtual menjadi seseorang masuk ke dalam klasifikasi wisatawan tanpa mempertimbangkan aspek spasial yang dulunya mengharuskan kategorisasi berdasarkan jarak antar destinasi asal dengan tujuan. Selain beberapa alasan tersebut, yang cukup krusial adalah lalainya UNWTO melihat aspek-aspek mikro yang berimplikasi terhadap pemahaman masyarakat luas terhadap terminologi 'wisatawan' (Erik Cohen \& Cohen, 2012; McCabe, 2005; Pernecky \& Jamal, 2010).

Untuk mengurai dan memberikan pemahaman yang lebih komprehensif, maka artikel ini akan mencoba untuk melihat terminologi wisatawan dalam dua perspektif. Untuk mempermudah pemahaman terhadap artikel, maka tulisan ini dibagi akan menjadi dua bagian besar. Pertama, diskusi terkait terminologi siapa itu wisatwan dikaji dalam perspektif akademis. Pada bagian ini definisi-definisi wisatawan secara runut akan disajikan. Kedua, dengan memahami definisi wisatawan yang terus berkembang, maka tulisan ini mencoba melihat wisatawan dalam tinjauan praktis yang berkembang namun tetap memiliki nilai akademis sehingga layak untuk dijadikan bahan kajian. Perkembangan disiplin ilmu sebagai bagian fundamental dari perkembangan ini juga akan disajikan.

\section{METODE PENELITIAN}

Tulisan ini mempergunakan studi literatur dengan basis studi bibliometri. Metode studi literatur merupakan serangkaian proses yang berhubungan dengan metode pengumpulan data pustaka, membaca dan mencatat, serta mengelolah data yang tersedia (Pahlevan-Sharif et al., 2019). Meskipun merupakan tipologi desk reseach, studi kepustakaan memberi implikasi terhadap pengembangan aspek teoritis dan aspek manfaat praktis dari sebuah topik.

Sebagai sebuah esensi penelitian, kajian literatur dilakukan oleh setiap peneliti untuk mendapatkan dan memetakan fondasi atas bangunan teori yang ingin dikonstruksikan lebih lanjut. Kajian literatur menjadi dasar pijakan atau fondasi untuk mengembangkan landasan teori, kerangka berpikir, serta hipotesis sementara (Creswell, 2013). Melalui kajian pustaka, peneliti dapat menggelompokkan, mengorganisasikan, serta mempergunakan variasi pustaka dalam bidangnya. Melalui studi kepustakaan, peneliti akan memiliki pendalaman yang lebih komprehensif terhadap masalah yang hendak diteliti.

Studi literatur adalah mencari referensi teori yang relevan dengan kasus atau permasalahan yang ditemukan (Koseoglu et al., 2016). Referensi ini dapat dicari dari berbagai sumber literatur, baik digital maupun cetak dari buku, jurnal, artikel laporan penelitian,dan sebagainya. Studi literatur juga menjadi salah satu basis studi yang baik untuk mendapatkan gap riset sehingga novelty dalam riset dapat tercapai.

\section{HASIL DAN PEMBAHASAN}

\subsection{Terminologi wisatawan dalam} kajian akademis

Dalam perspektif akademis, kajian tentang wisatawan telah tercatat dan terpublikasikan di Scopus pada tahun 1953 dengan lebih dari enam puluh ribu dokumen. Sebagaimana yang tampak 
pada gambar 2 dibawah ini, studi tentang wisatawan terus menjadi kajian menarik dan banyak menjadi perhatian para peneliti. Hal ini terlihat dari semakin bertambahnya jumlah publikasi dari tahun ke tahun.

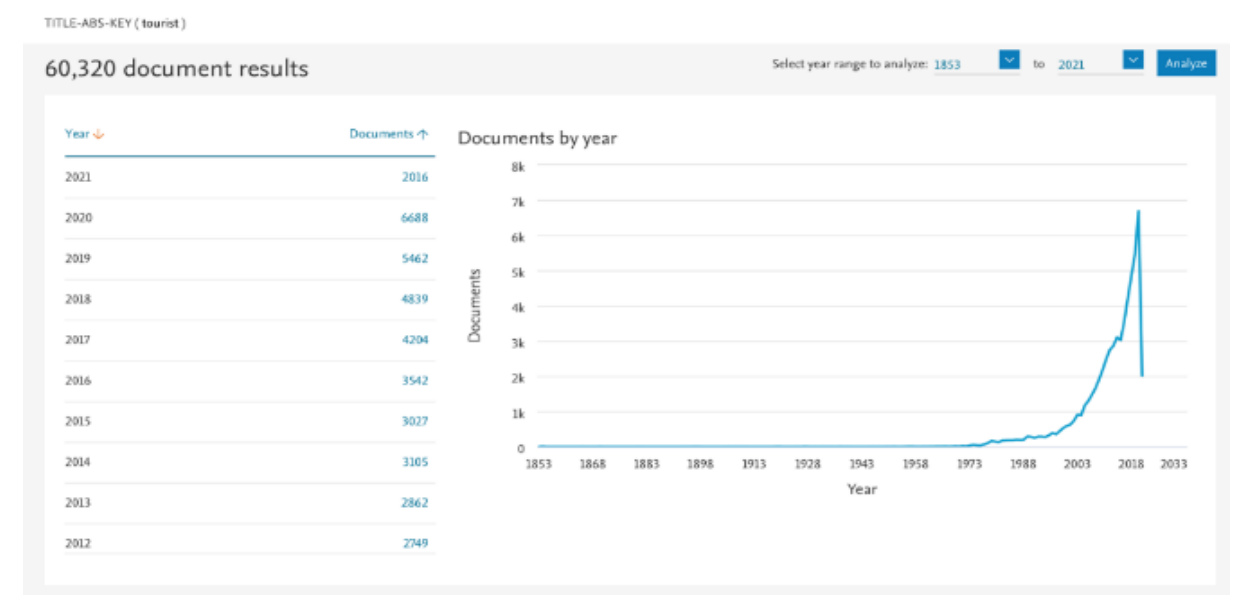

Gambar 2. Publikasi dengan kata kunci "wisatawan” di Scopus

[Sumber: Scopus, 2021]

Telah banyak peneliti baik nasional maupun internasional yang mencoba untuk mendefinisikan siapa itu wisatawan dalam beragam perspektif. Secara ekplisit beberapa peneliti yang mendefinisikan wisatwan sebagai elemen bahkan bagian dari perkembangan sosial budaya sebuah destinasi (Gilles, 2015; Muzaini, 2006; Shishmanova, 2015). Hal ini tentu saja memperdebatkan beberapa tulisan yang mengganggap wisatawan bertanggung jawab terhadap perubahan social budaya masyarakat yang nantinya merubah destinasi tersebut. Misalnya tulisan (Doxey, (1975) Butler (1980), mengekplorasi hubungan antara wisatawan dengan masyarakat lokal. Menurut ButlerDoxey, penerimaan masyarakat dibagi kedalam empat fase yaitu euphoria, apathy, annoyance dan antagonism. Butler Doxey kemudian membagi fase-fase tersebut ke dalam dua penentu tingkat penerimaan yaitu berdasarkan waktu dan jumlah wisatawan. Butler Doxey berpendapat semakin besar jumlah wisatawan yang datang ke destinasi dalam waktu tertentu akan menyebabkan masyarakat yang 'anti wisatawan'.
Baik McCabe maupun Butler Doxey telah mewacanakan konsep quality tourism yang benar saat ini menjadi isu strategis dalam pengembangan pariwisata berkelanjutan-yang sebenarnya sangat bergantung pada preferensi wisatawan melakukan perjalanan. Bagaimanapun juga destinasi yang menarik akan selalu menjadi on the bucket list wisatawan, terutama bagi mereka yang baru pertama kali melakukan perjalanan. Ini juga yang nantinya berpotensi dengan apa yang disebut sebagai overtourism (Capocchi et al., 2019; Miller et al., 2010; Postma \& Schmuecker, 2017).

Selain memberi peluang terjadinya mismanagement destinasi akibat populasi wisatawan yang berlebih, wisatawan juga berpotensi untuk mengubah produk destinasi baik itu produk yang bersifat tangible ataupun intangible. Konsep ini nantinya disebut sebagai co-creation (Pitanatri, 2018; Schuckert et al., 2018; Sugathan \& Ranjan, 2019) yang kemudian oleh beberapa ahli seringkali disebut sebagai bentuk komodifikasi (Duffy \& Overholt, 2013; Picard, 2008). Dalam konsep ini tentu wisatawan tidak hanya dibagi ke dalam karakteristik tertentu, apalagi 
Sastri Pitanari, Uttari Pitanatri

berdasarkan aktivitas tertentu. Hal ini kemudian yang menjadi perkembangan definisi wisatawan saat ini. Untuk memberi gambaran secara lebih komprehensif, berikut disampaikan definisi wisatawan pada tabel 1 berikut ini.

Tabel 1. Resensi definisi wisatawan

[Sumber: Konstruk Penulis, 2021]

\begin{tabular}{ll}
\hline No & \multicolumn{1}{c}{ Definisi } \\
\hline $1 . \quad$ "One who travels for pleasure" \\
2. $\quad$ "One who travels for pleasure or \\
culture" \\
3. \\
a. $\quad \begin{array}{l}\text { someone who visits a place for } \\
\text { pleasure and interest, usually } \\
\text { while they are on holiday: }\end{array}$ \\
b. $\begin{array}{l}\text { UK a member of a sports team } \\
\text { who is travelling from place to } \\
\text { place in a foreign country, } \\
\text { playing games }\end{array}$
\end{tabular}

4. “Tourist's characteristics such as: permanency, voluntary-ness, direction, distance, recurrence and purpose of trip".

"The organised mass tourist, the individual mass tourist, the explorer and the drifter"

\section{5. "The act of being a tourist that defines the experience as such in a self-referential and indivisible way"}

6. 'tourist' as 'subject' and the wider representations of the tourist experience".
(Cohen, 1984, 1985, 1987;

Cohen \& Cohen, 2012; Cohen et al., 2014)

Wang (1999)

Cary (2004)
Membagi karakteristik wisatawan dimana, seseorang baru dikatan wisatawan jika berada dalam lima spectrum yang disampaikan oleh Cohen; seperti durasi perjalanan, jarak, revisit dan alas an melakukan perjalanan.

Cohen juga membagi tipologi wisatawan kedalam empat bagian yang dibuat berdasarkan pengalaman yang ingin didapat- mulai dari wisatawan yang "ingin cari aman" sampai tipologi off the beaten track yang ingin mencari destinasi yang belum dikunjungi wisatawan lainnya (explorer)

Wang mendefinisikan wisatawan tidak dalam perspektif pengalaman yang ingin dicari namun bagaimana perilaku wisatawan referensikan dirinya dan menjadi tidak terpisahkan dari elemen pengalaman tersebut.

Menurut Cary, justru wisatawan yang seharusnya sebagai subjek dari definisi itu sendiri, bukan pengalaman yang dilakukan oleh wisatawan 
7. "Expectations and behaviours of different groups"

8. “...because anyone can be categorised in any number of different ways, the choice of category used in any given situation or interaction allows for quite rich inferential analysis"

9. "Tourism comprises the activities of persons traveling to and staying in places outside their usual environment for not more than one consecutive year for leisure, business and other purposes"
(E. Cohen \& Noy, 2005; Jacobsen et al., 2019; Uriely, 2005)

(Benwell \& Stokoe, 2006)

(United Nations World Tourism Organization, 2018; 1983; UNWTO \& ILO, 2014)

10. - Orang-orang yang sedang melakukan perjalanan untuk bersenang-senang, alasan pribadi, kebutuhan kesehatan dan sebagainya.

- $\quad$ Orang-orang yang melakukan perjalanan untuk maksud menghadiri pertemuan, konferensi, atau di dalam hubungan sebagai utusan berbagai badan/organisasi (ilmu pengetahuan, administrasi, diplomatik, olahraga, keagamaan, dan sebagainya).
(Pitana \&

Gayatri., 2005;

Pendit, 2002)

tersebut.

Beberapa peneliti mendefinisikan wisatawan dan membaginya kedalam kelompok berdasarkan perilaku yang sama-misalnya wisatawan melakukan aktivitas yang sama atau memiliki preferensi yang sama saat berwisata. Jika mereka mencari pengalaman makan maka disebut gastronomy tourist, jika mereka mencari petualangan, maka disebut adventure tourist.

Benwell dan Stokoe melihat bahwa wisatawan itulah yang kemudian mengubah sebutan "wisatawan" menjadi aktivitas yang dilakukannya, misalnya 'leisure travel' jika ia merupakan tipologi pencari kesenangan, backpacker jika ia bepergian dengan backpack dengan budget terbatas. Begitu juga dengan sebutan 'traveller', 'holidaymaker', 'vacationer', 'pilgrim' dan sebagainya.

Wisatawan adalah orang yang mengadakan perjalanan dari tempat kediamannya tanpa menetap di tempat yang didatanginya atau hanya untuk sementara waktu tinggal di tempat yang didatanginya. UNWTO menyebut wisatawan sebagai pelancong yang melakukan perjalanan pendek.

Lebih lanjut menurut organisasi ini, wisatawan adalah orang yang melakukan perjalanan ke sebuah daerah atau negara asing dan menginap minimal 24 jam atau maksimal satu tahun di tempat tersebut

Dalam penjelasan ini, Pendit mengklasifikasikan wisatwan berdasarkan motif perjalannya, apakah bersenang-senang, perjalanan dinas, bisnis maupun kunjungan yang bersifat kenegaraan 


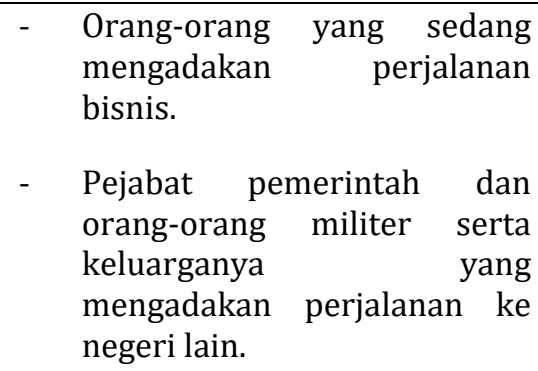

Selain pendekatan diatas, wisatawan juga memiliki beragam motif, minat, ekspektasi, karakteristik sosial, ekonomi serta budaya yang berbeda. Dengan motif dan latar belakang yang berbeda, maka mereka menjadi episentrum dalam menciptakan permintaan produk dan jasa wisata di destiansi. Dalam penciptaan produk pariwisata, peran ini sangat menentukan serta menjadi esensi dari kegiatan pariwisata. Oleh sebab itu, wisatawan turut "mengubah" destinasi. Sebagai contoh saat wisatawan Jepang menjadi pasar utama di Bali, salah satu kebutuhannya adalah masakan khas Jepang. Oleh sebab itu muncul restoranrestoran Jepang di Bali untuk memenuhi kebutuhan pasar tersebut. Dalam beberapa dekade, berkembang wisata gastronomi yang turut mempopulerkan kuliner local. Wisatawan Jepang juga turut mengikuti tren tersebut dan mulai mengapresiasi masakan local khas Bali (Pitanatri, 2016; Pitanatri \& Putra, 2016; Putra et al., 2018). Perubahan ini akan berimplikasi secara langsung pada kebutuhan wisata, yang dalam hal ini disebut permintaan wisata (tourism demand).

Dalam perspektif berbeda wisatawan juiga dapat diklasifikasikan dengan menggunakan dasar interaksi dan dasar kognitif normatif (Murphy: 1985). Pada tipologi atas dasar interaksi, penekanannya adalah sifat-sifat interaksi antara wisatawan dengan masyarakat lokal. Sedangkan tipologi atas dasar kognitif-normatif lebih menekankan pada motivasi yang melatarbelakangi perjalanan.

Dari pendapat Murphy, maka terminology wisatawan tetap akan menjadi kajian menarik dalam beberapa dekade mendatang. Perubahan terhadap motivasi, perilaku serta pengaruh eksternal akan semakin memperkaya khazanah ilmu pariwisata itu sendiri. Apa yang dulu tidak disinggung dalam kajian, menjadi gap yang terbuka untuk dapat didalami lebih lanjut.

\subsection{Terminologi wisatawan dalam perkembangan praktis}

Dalam perkembangan praktis, tipologi wisatawan berkembang sedemikian pesatnya sejalan dengan laju perkembangan pariwisata dunia. Perkembangan tipologi ini turut menimbulkan perubahan konstruk dalam terminologi wisatawan. Wisatawan pun tidak lagi hanya berdasarkan pendekatan spasial dan temporal, namun konsep yang berkembang juga jenis wisatawan virtual yang tidak dapat didefinisikan dengan pendekatan konvensional. Lebih lanjut, hal ini tidak terlepas dari perkembangan teknologi terutama transportasi dan digital dalam konteks "mobility" atau pergerakan wisatawan (Salazar \& Salazar, 2021; Sheller, 2014). Sebagai contoh seorang asal Jakarta dapat melakukan site incpection di Singapore, makan siang di Malaysia kemudian rapat di Thailand akhirnya makan malam sambil membeli saree di India. Pertanyaannya, apakah ia termasuk dalam klasifikasi wisatawan? Dalam pendekatan akademis, hal ini tentu menjadi diskusi dan perdebatan tersendiri. Namun, sebagai sebuah fenomena yang semakin berkembang, dalam perjalannya hal ini akan menciptakan berbagai teori baru- 
Sastri Pitanari, Uttari Pitanatri

dimana pariwisata mungkin juga akan menemukan bentuk baru.

Konsep perjalanan wisatawan sebagaimana teori lama mendefinisikan sekurang-kurangnya menginap selama 1x24 jam mungkin akan tidak relevan di masa yang akan datang. Konsep mobility yang begitu dekat dengan teknologi tentu akan melahirkan perspektif metodologis baru. Oleh sebab itu, pariwisata sebaiknya dikaji dalam dimensi keilmuan yang bervariasi sehingga menimbulkan research outcome yang memperkaya keilmuan itu sendiri. Melihat perkembangan ini, berikut disampaikan klasifikasi wisatawan sebagai pengembangan konsep UNWTO yang merujuk pada riset-riset dengan pendekatan baru.

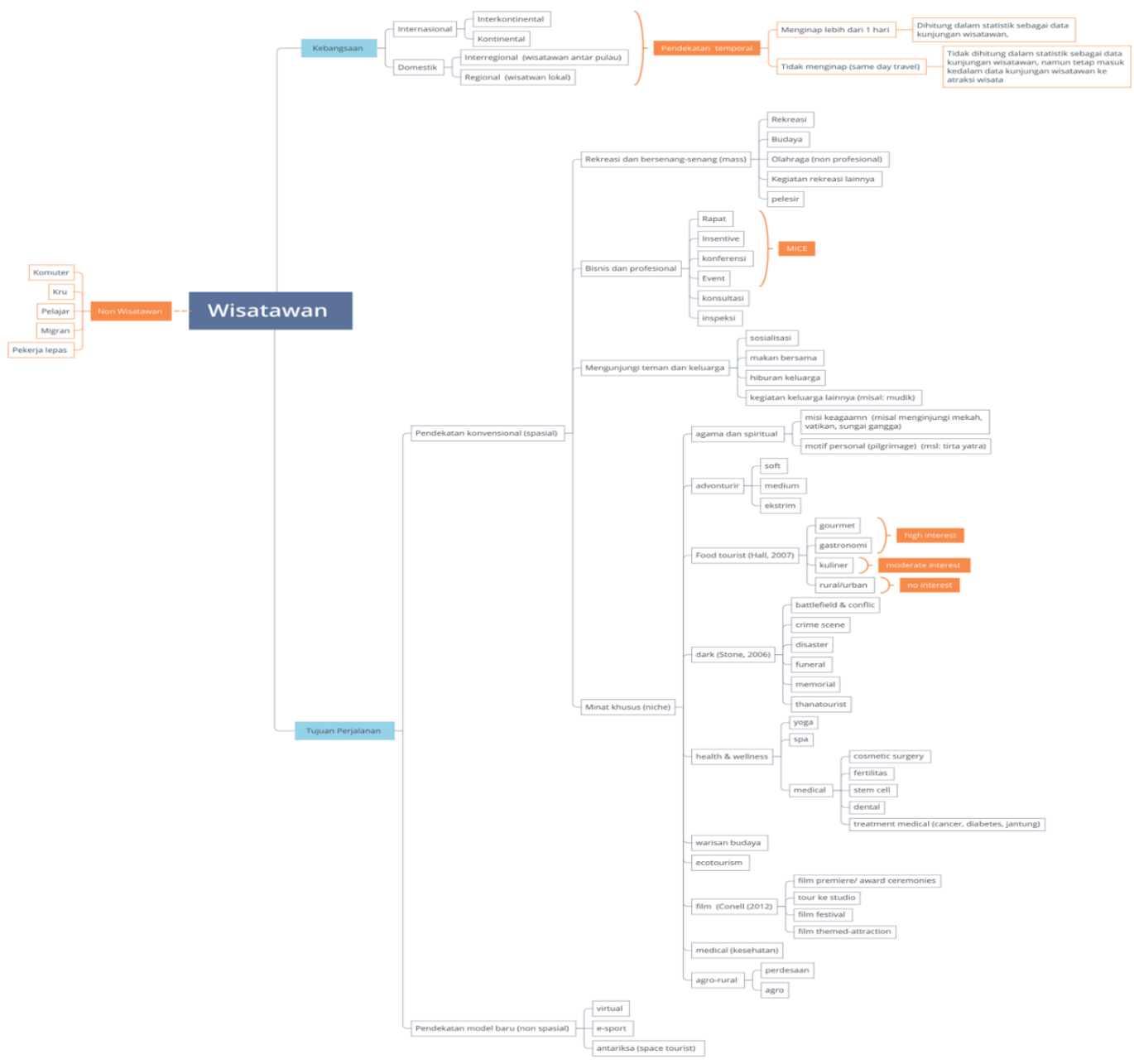

Gambar 3. Perkembangan Klasifikasi Wisatawan

[Sumber: Ilustrasi Penulis, 2021]

Pada gambar diatas, tampak bahwa spektrum-spektrum baru pariwisata akan terbentuk dan semakin dinamis dengan semakin bertambahnya kebutuhan orang untuk melakukan perjalanan. Perkembangan ini sesuai dengan apa yang disampaikan Coles et al., (2009) yang menyatakan bahwa sejatinya pariwisata merupakan ilmu, yang multidisiplin sehingga pendekatan metodologis yang harus dilakukan dapat berbentuk Multidisplinary Interdiciplinary dan Trans disciplinary. Pandangan ini juga disampaikan oleh Choi dan Park (2007) yang menekankan betapa pentingnya riset-riset yang menggabungkan beberapa disiplin sekaligus. Therefore, there has been an 


\begin{tabular}{ll}
\hline Sastri Pitanari, Uttari Pitanatri & \\
increased emphasis on research involving & dari MIPA untuk studi-studi longitudinal. \\
multiple disciplines (Park et al., 2019) & Apakah ada perubahan intensi \\
Dengan adanya perkembangan & wisatawan gastronomi asal Jepang \\
wisatawan dan pariwisata, maka & terhadap masakan local selama sepuluh \\
dibutuhkan metode riset baru yang tidak & tahun terakhir? Hal ini tentu saja sangat \\
kaku. Pariwisata sebagai sebuah turunan & sulit dipotret dengan metode \\
dari ilmu sosial, sejatinya memberikan & konvensional (misal penyebaran \\
kesempatan bagi peneliti lintas disiplin & kuesioner). Untuk lebih mempermudah \\
untuk menuangkan kajian dalam & pemahaman antara ketiga bentuk \\
perspektif yang baru. Sebagai contoh, & tersebut, berikut disampaikan \\
saat ingin melakukan terhadap kajian & karakteristik dan perbedaan ketiga \\
wisatawan gastronomi, maka untuk & disiplin yang dapat menjadi pegangan \\
mendapatkan hasil riset yang lebih tajam & saat melakukan riset-riset pariwisata \\
dibutuhkan kolaborasi dengan peneliti & terbarukan.
\end{tabular}

Tabel 2. Karakteristik dari riset Multi/Inter/Trans disciplinary dalam pariwisata

[Sumber: Resensi dan Elaborasi Penulis terhadap tulisan Okumus et al., 2018)

\begin{tabular}{|c|c|c|c|}
\hline Dimensi & Riset Multidisiplin & Riset Interdisiplin & Riset Transdiciplin \\
\hline Kolaborasi & $\begin{array}{l}\text { Peneliti dari berbagai } \\
\text { disiplin ilmu bekerja } \\
\text { secara mandiri. }\end{array}$ & $\begin{array}{l}\text { Peneliti dari berbagai } \\
\text { disiplin ilmu bekerja sama } \\
\text { dalam sebuah riset. }\end{array}$ & $\begin{array}{l}\text { Peneliti dari berbagai disiplin } \\
\text { ilmu, serta pemangku } \\
\text { kepentingan dan non- } \\
\text { akademis, bekerja bersama } \\
\text { untuk sebuah riset. }\end{array}$ \\
\hline Style/time & $\begin{array}{l}\text { Peneliti dari berbagai } \\
\text { disiplin ilmu bekerja } \\
\text { pada berbagai aspek } \\
\text { riset. }\end{array}$ & $\begin{array}{l}\text { Peneliti dari berbagai } \\
\text { disiplin ilmu bekerja } \\
\text { bersama untuk aspek yang } \\
\text { sama. }\end{array}$ & $\begin{array}{l}\text { Peneliti dari berbagai disiplin } \\
\text { ilmu bekerja bersama } \\
\text { menggunakan kerangka kerja } \\
\text { konseptual bersama. }\end{array}$ \\
\hline Tujuan & $\begin{array}{l}\text { Peneliti memiliki tujuan } \\
\text { penelitian yang terpisah. }\end{array}$ & $\begin{array}{l}\text { Peneliti memiliki tujuan } \\
\text { yang sama }\end{array}$ & $\begin{array}{l}\text { Peneliti telah berbagi tujuan } \\
\text { dan merupakan expert di } \\
\text { bidang masing-masing. }\end{array}$ \\
\hline $\begin{array}{l}\text { Peran } \\
\text { peneliti }\end{array}$ & $\begin{array}{l}\text { Peneliti memiliki peran } \\
\text { yang terpisah tetapi } \\
\text { saling terkait. }\end{array}$ & $\begin{array}{l}\text { Peneliti memiliki peran } \\
\text { yang sama. }\end{array}$ & $\begin{array}{l}\text { Peneliti memiliki pelepasan } \\
\text { peran dan perluasan peran. }\end{array}$ \\
\hline Aturan & $\begin{array}{l}\text { Peneliti menjaga aturan } \\
\text { disiplin mereka. }\end{array}$ & $\begin{array}{l}\text { Peneliti menyerahkan } \\
\text { beberapa aspek aturan } \\
\text { disiplin mereka. }\end{array}$ & $\begin{array}{l}\text { Peneliti mengembangkan } \\
\text { kerangka kerja konseptual } \\
\text { bersama, menggambar dari } \\
\text { basis disiplin khusus. }\end{array}$ \\
\hline Batasan & $\begin{array}{l}\text { Peneliti tidak menentang } \\
\text { batas disiplin mereka. }\end{array}$ & $\begin{array}{l}\text { Mengaburkan batas } \\
\text { disiplin. }\end{array}$ & Melampaui disiplin \\
\hline Metodologi & Metodologi terpisah & $\begin{array}{l}\text { Metodologi umum / } \\
\text { bersama }\end{array}$ & Multi metodelogi \\
\hline \multirow[t]{2}{*}{ Outcome } & $\begin{array}{l}\text { Outcome dari riset } \\
\text { merupakan hasil dari } \\
\text { masing-masing peneliti } \\
\text { yang dirangkum menjadi } \\
\text { satu }\end{array}$ & $\begin{array}{l}\text { Karena berada dalam } \\
\text { disiplin yang sama, hasil } \\
\text { riset biasanya } \\
\text { menghasilkan lebih banyak } \\
\text { dari hasil peneliti yang } \\
\text { dirangkum. }\end{array}$ & $\begin{array}{l}\text { Outcome dari riset merupakan } \\
\text { hasil bersama }\end{array}$ \\
\hline & & \begin{tabular}{lrr} 
Sebagai & contoh riset \\
motivasi & \multicolumn{2}{c}{ wisatawan } \\
berwisata & tidak hanya \\
menghasilkan & preferensi \\
namun & mungkin
\end{tabular} & \\
\hline
\end{tabular}




\begin{tabular}{|c|c|c|c|}
\hline & & $\begin{array}{l}\text { pengeluaran (expenditure), } \\
\text { pola perjalanan, social } \\
\text { budaya dan sebagainya }\end{array}$ & \\
\hline $\begin{array}{l}\text { Contoh } \\
\text { (dalam }\end{array}$ & Salad & Melting pot (Panci Lebur) & Sebuah kue \\
\hline $\begin{array}{l}\text { Choi \& } \\
\text { Pak, 2007) }\end{array}$ & $\begin{array}{l}\text { Artinya masing-masing } \\
\text { disiplin masih terlihat } \\
\text { perbedaannya. Tomat } \\
\text { bentuknya pasti berbeda } \\
\text { dengan selada }\end{array}$ & $\begin{array}{l}\text { Artinya disiplin akan } \\
\text { melebur menjadi satu } \\
\text { dalam riset ini. Sehingga } \\
\text { semuanya melebur menjadi } \\
\text { satu. Meskipun demikian, } \\
\text { jika ditelusuri lebih lanjut } \\
\text { masih dapat dibedakan } \\
\text { antara rasa tomat dengan } \\
\text { rasa daging. }\end{array}$ & $\begin{array}{l}\text { Artinya seluruh disiplin akan } \\
\text { mengeluarkan satu bentuk } \\
\text { baru. Telur, terigu, susu dan } \\
\text { mentega akhirnya membentuk } \\
\text { sebuah kue setelah melalui } \\
\text { proses pemanggangan. Di akhir } \\
\text { proses sudah tidak dapat } \\
\text { dilihat lagi perbedaan antara } \\
\text { satu bahan dengan bahan yang } \\
\text { lain. }\end{array}$ \\
\hline
\end{tabular}

Dari tabel di atas maka dapat dilihat bagaimana perkembangan pariwisata sebagai sebuah ilmu kedepannya akan semakin progresif. Jika merujuk ke belakang, perjalanan adalah sebuah aktivitas yang sangat ekslusif di Eropa karena biasanya diperuntukkan untuk alasan kesejahteraan, keagaman dan kemasyuran (Gold-Gospel-Glory). Mobilitas kemudian berkembang sebagai sebuah aktivitas borderless dengan salah satu aktor utamanya yang disebut wisatawan. Oleh sebab itu, selama ada pergerakan wisatawan, maka terminology wisatawan akan terus bersifat dinamis. Wisatawan kedepannya tidak lagi didefinisikan secara kaku namun akan lebih mengacu pada ciri khas dari perjalanan tersebutwisatawan gastronomi yang akan memiliki ciri khas berbeda dari wisatawan adventurir.

\section{KESIMPULAN}

Dengan melihat berbagai terminology di atas, maka dapat pertanyaan siapa itu wisatawan dapat dipahami sebagai pengembangan dari studi pariwistata. Meskipun kriteriakriteria dasar seorang wisatawan harus dipenuhi dan menjadi kesepakatan

\section{DAFTAR PUSTAKA}

Benwell, B., \& Stokoe, E. (2006). Discourse and identity. Edinburgh University Press. global, perlu dipahami bahwa terbuka peluang bagi penelitian selanjutnya dalam mengeksplorasi terminologi baru wisatawan. Seperti saat ini berkembang istilah-istilah yang tidak terekspos sebelum tahun 2000an dekade lalus seperti perkembangan dark tourist bahkan LGBT (Lesbian Gay Biseksual dan Trangender) tourist-yang meskipun sangat kontroversial namun saat ini ternyata telah menjadi target market banyak destinasi dunia. Beberapa Negara seperti Thailand misalnya bahkan telah melabel Negara-nya sebagai LGBT friendly destination.

Salah satu bukti lagi bahwa terjadi co-creation (meskipun sangat kontroversial) terjadi antara destinasi dengan wisatawan yang datang ke destinasi tersebut. Oleh karena itu, memaknai wisatwan local, sejatinya merupakan "kesepakatan" antara stakeholder terkait. Terminologi 'wisatawan' sebenarnya akan terus berkembang dan merupakan pengembangan dari ilmu pariwisata baik secara konseptual maupun dalam terminologi praktis. Maka mengakhiri tulisan ini, sejatinya yang abadi adalah perubahan itu sendiri.

Boztug, Y., Babakhani, N., Laesser, C., \& Dolnicar, S. (2015). The hybrid tourist. Annals of Tourism Research, 54 ,
190-203. 
https://doi.org/10.1016/j.annals.20 15.07.006

Capocchi, V., Pierotti, A. \& Capocchi. (2019). Overtourism: A Literature Review to Assess Implications and Future Perspectives. Sustainability, 11(12), 3303. https://doi.org/10.3390/su1112330 3

Cohen, E., \& Noy, C. (2005). Conclusion: The backpackers and Israeli society. In Israeli Backpackers: From Tourism to Rite of Passage.

Cohen, E. (1984). The sociology of tourism: approaches, issues, and findings. Annual Review of Sociology, 10(1), 373-392.

Cohen, E. (1985). The tourist guide: The origins, structure and dynamics of a role. Annals of Tourism Research, 12(1), 5-29.

Cohen, E. (1987). The tourist as victim and protégé of law enforcing agencies. Leisure Studies, 6(2), 181198.

Cohen, E, \& Cohen, S. A. (2012). Current sociological theories and issues in tourism. In Annals of Tourism Research (Vol. 39, Issue 4, pp. 21772202). Elsevier Ltd. https://doi.org/10.1016/j.annals.20 12.07.009

Cohen, S. A., Prayag, G., \& Moital, M. (2014). Consumer behaviour in tourism: Concepts, influences and opportunities. Current Issues in Tourism, 17(10), 872-909.

Coles, T., Hall, C. M., \& Duval, D. T. (2009). Post-disciplinary tourism. In Philosophical issues in tourism (pp. 80-100). Channel View Publications.

Creswell, J. W. (2013). Qualitative Inquiry and Research Design. In Qualitative Inquiry and Research Design (pp. 53-100).

Doxey, G. V. (1975). A causation theory of visitor-resident irritants: Methodology and research inferences. Travel and Tourism Research Associations Sixth Annual Conference Proceedings, 195-198.
Duffy, L. N., \& Overholt, J. R. (2013). Seeking Authenticity: Reconceptualizing Adventure Tourism. Illuminare: Seeking Authenticity: ReConceptualizing Adventure Tourism Illuminare: A Student Journal in Recreation, Parks, and Leisure Studies, 11(1), 45-59. http://scholarworks.iu.edu/journals /index.php/illuminare/

Gde, P., Pitana, P., \& Gayatri, G. (2005). Sosiologi Pariwisata. Andi: Yogyakarta.

Gilles, A. (2015). The social construction of Guangzhou as a translocal trading place. Journal of Current Chinese Affairs, 44(4), 17-47. https://doi.org/10.1177/186810261 504400403

Glaesser, D., Kester, J., Paulose, H., Alizadeh, A., \& Valentin, B. (2017). Global travel patterns: An overview. Journal of Travel Medicine, 24(4), 15.

https://doi.org/10.1093/jtm/tax007

Jacobsen, J. K. S., Iversen, N. M., \& Hem, L. E. (2019). Hotspot crowding and over-tourism: Antecedents of destination attractiveness. Annals of Tourism Research. https://doi.org/10.1016/j.annals.20 19.02.011

Kompas. (2020). Apa Itu Staycation? Liburan yang Diprediksi Jadi Tren Selama Pandemi. https://travel.kompas.com/read/20 20/07/29/094500127/apa-itustaycation-liburan-yang-diprediksijadi-tren-selamapandemi?page=all\#: :text=Sementar a menurut Inn on the,hanya untuk keluar dari rumah.

Koseoglu, M. A., Rahimi, R., Okumus, F., \& Liu, J. (2016). Bibliometric studies in tourism. Annals of Tourism Research. https://doi.org/10.1016/j.annals.20 16.10.006

McCabe, S. (2005). 'Who is a tourist?' A critical review. Tourist Studies, 5(1), 85-106.

McCabe, S. (2019). Marketing Communications in Tourism and 
Hospitality: Concepts, Strategies and Cases. In S. McCabe (Ed.), Journal of Destination Marketing and Management. Elsevier. https://doi.org/10.1016/j.wep.2019. 07.001

Miller, G., Rathouse, K., Scarles, C., Holmes, K., \& Tribe, J. (2010). Public understanding of sustainable tourism. Annals of Tourism Research. https://doi.org/10.1016/j.annals.20 09.12.002

Muzaini, H. (2006). Backpacking Southeast Asia: Strategies of "looking local." Annals of Tourism Research, 33(1), 144-161. https://doi.org/10.1016/j.annals.20 mmmmmmmmmnnnnn05.07.004

Okumus, F., van Niekerk, M., Koseoglu, M. A., \& Bilgihan, A. (2018). Interdisciplinary research in tourism. Tourism Management, 69(May), 540-549. https://doi.org/10.1016/j.tourman.2 018.05.016

Pahlevan-Sharif, S., Mura, P., \& Wijesinghe, S. N. R. (2019). A systematic review of systematic reviews in tourism. Journal of Hospitality and Tourism Management, 39, 158-165. https://doi.org/10.1016/j.jhtm.2019 .04 .001

Paris, C. M. (2012). FLASHPACKERS: An Emerging Sub-Culture? Annals of Tourism Research, 39(2), 10941115.

https://doi.org/10.1016/j.annals.20 11.12.001

Pendit, N. S. (2002). Ilmu pariwisata. Jakarta: Pradnya Paramita.

Pernecky, T., \& Jamal, T. (2010). (Hermeneutic) Phenomenology in tourism studies. Annals of Tourism Research, 37(4), 1055-1075. https://doi.org/10.1016/j.annals.20 10.04 .002

Picard, M. (2008). Balinese identity as tourist attraction: From 'cultural tourism' (pariwisata budaya) to 'Bali erect' (ajeg Bali). Tourist Studies, $8(2)$,

155-173. https://doi.org/10.1177/146879760 8099246

Pitanatri, P. D. . (2016). Inovasi Dalam Kompetisi: Usaha Kuliner Lokal Menciptakan Keunggulan Kompetitif Di Ubud. Jurnal Master Pariwisata (JUMPA), $3, \quad 1-14$. https://doi.org/10.24843/jumpa.20 16.v03.i01.p01

Pitanatri, P. D. . (2018). Esensi dalam Eksistensi: Sharing economy pada pengelolaan homestay tiga destinasi prioritas di Indonesia (P. D. S. Mertha, I Wayan, Pitanatri (ed.)). Pusat Penelitian dan Pengabdian Kepada Masyarakat Sekolah Tinggi Pariwisata Nusa Dua Bali. https://www.researchgate.net/publi cation/325143483_ESENSI_DALAM_ EKSISTENSI_SHARING_ECONOMY_P ADA_PENGELOLAAN_HOMESTAY_TI GA_DESTINASI_PRIORITAS_DI_INDO NESIA?_sg=feDE8C2o5LzHwApZpFUj _Q213NGi65tP6R_56ysqbntctumRwf nzHOgyVb_rPJYGNKBgORC8M9W8opDiyA0JCxDxRR91ilW

Pitanatri, P. D. S. (2020). Wisatawan Flashpacker: Sebuah Pendekatan Epistemologis. Jurnal Master Pariwisata (JUMPA), 7(1), 77. https://doi.org/10.24843/JUMPA.20 20.v07.i01.p04

Pitanatri, P. D. S., \& Putra, I. N. D. (2016). Wisata Kuliner Atribut Baru Destinasi Ubud. JagatPress.

Postma, A., \& Schmuecker, D. (2017). Understanding and overcoming negative impacts of tourism in city destinations: conceptual model and strategic framework. Journal of Tourism Futures, 3(2), 144-156. https://doi.org/10.1108/JTF-042017-0022

Putra, I. N. D., Raka, A. A. G., Yanthy, P. S., Aryanti, N. N. S., \& Pitanatri, P. D. S. (2018). Wisata Gastronomi UbudGianyar.

Ramdhani, G. (2020). Staycation ke Bali, Ini Resort Villa Bintang 4 dengan Private Pool di Bawah Rp 1 Juta. Liputan6.Com.

https://www.liputan6.com/lifestyle/ 
read/4419051/staycation-ke-baliini-resort-villa-bintang-4-denganprivate-pool-di-bawah-rp-1-juta

Richards, G. (2018). Cultural tourism: A review of recent research and trends. Journal of Hospitality and Tourism Management. https://doi.org/10.1016/j.jhtm.2018 .03 .005

Salazar, N. B., \& Salazar, N. B. (2021). Existential vs . essential mobilities: insights from before, during and after a crisis and after a crisis. Mobilities, $\quad 00(00), \quad 1-15$. https://doi.org/10.1080/17450101. 2020.1866320

Schuckert, M., Peters, M., \& Pilz, G. (2018). The co-creation of host-guest relationships via couchsurfing: a qualitative study. Tourism Recreation Research, 43(2), 220234.

https://doi.org/10.1080/02508281. 2017.1384127

Sheller, M. (2014). The new mobilities paradigm for a live sociology. Current Sociology, 62(6), 789-811. https://doi.org/10.1177/001139211 4533211

Shishmanova, M. V. (2015). Cultural Tourism in Cultural Corridors, Itineraries, Areas and Cores Networked. Procedia - Social and Behavioral Sciences, 188, 246-254. https://doi.org/10.1016/j.sbspro.20 15.03.382

Sugathan, P., \& Ranjan, K. R. (2019). Cocreating the tourism experience. Journal of Business Research, 100(December 2017), 207-217. https://doi.org/10.1016/j.jbusres.20 19.03.032

Tribe, J., \& Liburd, J. J. (2016). The tourism knowledge system. Annals of Tourism Research, 57, 44-61. https://doi.org/10.1016/j.annals.20 15.11.011

United Nations World Tourism Organization. (2018). Tourism and Culture Synergies. In Tourism and Culture Synergies. https://www.e- unwto.org/doi/pdf/10.18111/97892 84418978

UNWTO. (1983). Report on the Draft Tourism Bill of Rights and Tourist Code (A/5/18): UNWTO General Assembly Documents: Vol 1983, No 1. https://www.eunwto.org/doi/pdf/10.18111/unwto gad.1983.1.mk143x508438111n

UNWTO, \& ILO. (2014). Measuring Employment in the Tourism Industries - Guide with Best Practices. In Measuring Employment in the Tourism Industries - Guide with Best Practices. https://doi.org/10.18111/97892844 16158

Uriely, N. (2005). The tourist experience. Conceptual developments. Annals of Tourism Research, 32(1), 199-216. https://doi.org/10.1016/j.annals.20 04.07.00 